\title{
Comparison of two text message (mHealth) campaigns for the Deaf: Contracted out v. conducted in-house
}

\author{
D Hacking, Y K Lau, H J Haricharan, M Heap
}

\begin{abstract}
At the time of this study, Damian Hacking (MPH), Yan Kwan Lau (MPH), Hanne Jensen Haricharan (MA) and Marion Heap (PhD) were all working in the Health and Human Rights Programme, as part of the School of Public Health and Family Medicine, Faculty of Health Sciences, University of Cape Town, South Africa. Marion's research focuses on overcoming barriers to accessing health services by the Deaf community. Use of health technologies is one approach to overcoming these barriers, which is being investigated as part of ongoing research by second-language English speakers and the Deaf community.
\end{abstract}

Corresponding author: D Hacking (damianuct@gmail.com)

Cell phone-based health information (mobile health or mHealth) campaigns are an emerging technology. This evaluation focused on the aspect of cost of two health information campaigns, one on hypertension and one on pregnancy. Researchers could either contract out the technical components of the campaigns or attempt to run the campaigns themselves, in-house. The in-house campaigns cost an estimated ZAR13 $548.72 \mathrm{v}$. the private provider quotes which ranged from ZAR27 542.97 to ZAR34 227.59. Running the campaigns in-house was more labour intensive and required more technical expertise, but had a reduced delivery failure rate ( $9.2 \%$ in-house v. $30.0 \%$ private provider). Running small to medium SMS (text message) campaigns for evaluative purposes proved advantageous over contracting out to private providers. Larger-scale evaluations and full-scale roll-out will require the services of private providers, but it is still essential that researchers actively engage with and monitor the technical aspects of these campaigns. 


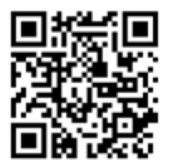

South Africa (SA) is increasingly adopting mobile health or mHealth interventions $^{[1]} \quad$ (the practice of medicine and public health with the use of mobile devices to enable communication between healthcare workers and patients), with cell phone-based campaigns increasingly seen as a means to bridge health information gaps. ${ }^{[2]}$ This is due in part to the high prevalence of cell phone ownership, even in resource-poor settings. ${ }^{[3]}$ South Africans often have more than one mobile phone subscription, with a ratio of 147 cell phone subscriptions per 100 people. ${ }^{[4]}$ As yet, however, there are relatively few comprehensive evaluations of these health information campaigns, especially of their cost. ${ }^{[5]}$ We report an evaluation of the cost of two campaigns in which the costs of outsourcing short message service (SMS, i.e. text message) campaigns to a service provider were compared with conducting them in-house. We comment on the advantages and disadvantages of both methods, including some of the technical challenges encountered in the process of carrying out in-house and outsourced SMS campaign evaluations.

\section{SMS campaigns}

Two SMS health information campaigns, one on hypertension and one on pregnancy (University of Cape Town Health Sciences Faculty Human Research Ethics Committee ethics reference numbers 043/2011 and 044/2011, respectively), were carried out in resource-poor settings in Cape Town, SA (2011 - 2013), among hearing clinic attenders at two public health facilities. ${ }^{[6,7]}$ The data capturing and storage of the baseline and exit questionnaires used to assess the effectiveness of these campaigns, as well as the management of the SMS campaigns, including opt-outs during the campaigns, were contracted out to a private provider.

Following this, two similar campaigns were carried out among signing deaf people (the Deaf) at similar socioeconomic but nonclinical sites. ${ }^{[8,9]}$ For the Deaf SMS campaigns, those aspects that had previously been contracted out were dealt with in-house. In both the hearing and Deaf campaigns the administration of the questionnaires and collection of all data was performed by in-house fieldworkers.

To capture baseline and exit data and store data for the Deaf SMS (in-house) campaigns, a Google Apps for Education subscription was purchased, and each fieldworker was given their own account. Google Forms was used to create baseline and exit questionnaires, which were accessed from General Packet Radio Service (GPRS)-enabled phones. Data were automatically uploaded onto a Google spreadsheet via form submission, and the entire database was exported for further analysis and construction of SMS mailing lists. For sending out of the SMSs, bulk SMSs were purchased from a mobile network service provider in SA. The online interface allowed for bulk SMSs to be scheduled on a calendar, for specific days and times. SMSs were directly imported from an SMS mailing list spreadsheet, and were scheduled on the calendar on a per-week basis, with individuals who opted out exiting the program at the end of the week. Each week a researcher ensured that bulk SMSs were set up, removed any opt-outs and tracked delivery failures for follow-up. Opt-outs were determined by asking participants to send two free 'please call me' SMSs to a dedicated cell phone in short succession in order to minimise costs to the user ('please call me' SMSs are a free service that allows mobile users to send a predetermined text message asking the recipient to call the senders number, and are available on all networks in SA).

\section{Comparison between outsourced and in-house}

The costs of running the in-house SMS campaigns, including human resources, were calculated at the end of the campaigns and compared with quotes received from private providers prior to initiation of the campaigns, adjusted for any changes in the campaigns (e.g. number of SMSs quoted for v. actual number of SMSs sent). In total the Deaf SMS campaigns cost an estimated ZAR13 548.72 to run (costs for 2014). Quotes for equivalent campaigns ranged from ZAR27 542.97 to ZAR34 227.59. Costs are divided into four sections, outlined in Table 1. In addition to these cost savings, $30.0 \%$ of all SMSs reported delivery failure to the participants by the private provider. In-house SMSs, on the other hand, had a delivery failure rate of $9.2 \%$ (10.4\% in the pregnancy campaign and $8.5 \%$ in the hypertension campaign).

There is some uncertainty surrounding the exact cost of the in-house campaigns, as the researchers who oversaw the training component were not hired specifically for this role, and so a cost of their time devoted to the campaigns was estimated. However, even if their costs were tripled, in-house would still be notably cheaper than the two private contractors. As such, completing the SMS campaigns in-house had considerable savings. Furthermore, if the lower delivery failure rate were to be factored into the cost of the SMS by looking at a cost per successful SMS sent, the savings would be even greater.

A considerable amount of management was required to set up the software and hardware for data capturing and recruitment. The Google interface was user friendly and allowed the creation of a questionnaire that could be accessed via the cell phones of the fieldworkers. The main advantage of this technique was that Google Forms had a high cross-compatibility with many phones, as long as they had basic internet access (Google Forms cannot capture data offline). The data were also kept in Google Cloud storage, which has the advantage of reducing the chance of data loss and increasing data accessibility, but could potentially have confidentiality issues if the security of the database was compromised. However, Google is one of the more secure cloud services, and after consultation with information technology experts, it was felt that this would not pose a significantly greater risk than conventional cabinet file storage. In addition, Google provides very useful security features, allowing administrators to

Table 1. Breakdown of costs for the Deaf SMS campaigns (in-house v. private contractor quotes) ${ }^{*}$

\begin{tabular}{|c|c|c|c|}
\hline & In-house & Private contractor 1 & Private contractor 2 \\
\hline Cost per SMS & $32 \mathrm{c}$ & $20 c$ & $50 \mathrm{c}$ \\
\hline Total SMSs sent & 10121 & 10121 & 10121 \\
\hline Total SMS cost & ZAR3 238.72 & ZAR2 024.20 & ZAR5 060.50 \\
\hline Administration fees & ZAR5 160.00 & ZAR28 000.00 & ZAR13 200.00 \\
\hline Training fees & $\sim$ ZAR5 $000.00^{\dagger}$ & & ZAR2 800.00 \\
\hline Software fees & $\sim$ ZAR $150.00^{\ddagger}$ & & ZAR300 \\
\hline Total (excl. VAT) & & ZAR30 024.20 & ZAR24 160.50 \\
\hline VAT & & ZAR4 203.39 & ZAR3 382.47 \\
\hline Total (incl. VAT) & ZAR13 548.72 & ZAR34 227.59 & ZAR27 542.97 \\
\hline \multicolumn{4}{|c|}{$\begin{array}{l}\text { "Costs are broken down into cost of SMSs sent, administration fees, training fees and software fees. Private contractor quotes } \\
\text { were broken down into these sections as well as we were able. } \\
\text { 'Training fees included setting up of the service in this case. Three research assistants were involved in this process. It is hard to } \\
\text { disentangle the exact cost of these three researchers; however, one was paid on an hourly basis, which was used in conjunction } \\
\text { with an estimate of relative contribution of the three researchers to arrive at this final figure. } \\
\text { Foftware fees were Google subscription fees (EUR10.00). These are charged per year. Our campaigns only lasted } 3 \text { months, but } \\
\text { the minimum subscription is for } 1 \text { year. }\end{array}$} \\
\hline
\end{tabular}


delete data remotely off a phone in the case of loss or theft of the phone and to vary the degree of data access per user.

Researchers were required to administer the in-house SMS campaigns continuously. Because mailing lists for SMSs could not be edited once scheduled, the SMSs were scheduled on a weekly basis to allow for any opt-outs. This required continuous administration and entry of the bulk SMSs. However, the same amount of work would still be required at the beginning to set up all bulk SMSs, and continuous administration would still be required to remove optouts. The researchers managing the campaigns had a vested interest in ensuring their success, and so were likely to micromanage them more efficiently and detect any problems that arose. Furthermore, researchers needed proficiency in cloud computing and mobile technologies. Our experience has been that this is not as daunting a task as it may seem at first. A baseline level of knowledge is required, but with enough training even modestly computer-literate researchers could engage with the campaigns. Furthermore, both Google and bulk SMS service providers provided effective and prompt troubleshooting services when needed.

While the use of a private provider obviated the need for both the setup and ongoing administration of the SMS campaigns, intense communication and monitoring of the private provider was still required. Data capturing of the in-house results was time intensive, as the Google system does not allow for automatic coding of responses, whereas the previously used private provider does. However, the coding from the private provider was not perfect and needed to be adjusted prior to analysis, so was not infallible either. Lastly, the in-house campaigns had a three times lower delivery failure rate than the private provider. This significantly improved the reliability of the results and therefore the strength of the conclusions.

\section{Conclusion}

In conclusion, we would strongly recommend that any group wishing to evaluate a small- to medium-scale mHealth project should consider doing it themselves using the readily available services. Not only is it cheaper, but it also allows for greater control over the campaigns, accountability and autonomy, which results in a better-run campaigns and more reliable research results. Larger-scale projects would probably need to be assigned to a private provider, but a degree of diligence is required to ensure that the services provided are correctly delivered and monitored.

\footnotetext{
1. Leon N, Schneider H. mHealth4CBS in SA. 2012. http://www.mrc.ac.za/healthsystems/MHealth4CBSReview. pdf (accessed 1 November 2014).

2. World Health Organization. mHealth: New Horizons for Health Through 414 Mobile Technologies. Geneva: WHO, 2011. http://www.who.int/goe/publications/goe_mhealth_web.pdf (accessed 1 November 2014).

3. Betjeman TJ, Soghoian SE, Foran MP. mHealth in sub-Saharan Africa. Int J Telemed Appl 2013;/an:482324. http://www.pubmedcentral.nih.gov/articlerender.fcgi?artid=3867872\&tool=pmcentr ez\&rendertype=abstract (accessed 1 August 2014).

ez\&rendertype=abstract (accessed 1 August 2014).
4. World Bank. 2013. http://data.worldbank.org/indicator/IT.CEL.SETS.P2 (accessed 26 August 2014).

4. World Bank. 2013. http://data.worldbank.org/indicator/IT.CEL.SETS.P2 (accessed 26 August 2014).
5. Vodopivec-Jamsek V, de Jongh T, Gurol-Urganci I, Atun R, Car J. Mobile phone messaging for preventive health care. Cochrane Database Syst Rev 2012, Issue 12. Art. No.: CD007457. [http://dx.doi. org/10.1002/14651858.CD007457.pub2

6. Lau YK, Cassidy T, Hacking D, Brittain K, Haricharan HJ, Heap M. Antenatal health promotion via short message service at a midwife obstetrics unit in South Africa: A mixed methods study. BMC Pregnancy Childbirth 2014;14(1):284. [http://dx.doi.org/10.1186/1471-2393-14-284]

7. Lau YK, Brittain K, Hacking D, Cassidy A, Haricharan HJ, Heap M. An evaluation of a short message service (SMS) hypertension health promotion at a community health centre (CHC) in Cape Town: A cautionary tale. Proceedings of the Public Health Association of South Africa Conference, Cape Town, 24 September 2013. https://www.phasa.org.za/ (accessed 20 November 2015).

8. Haricharan HJ, Heap M, Cassidy A, Lau YK, Hacking D. Bridging the language divide? Health

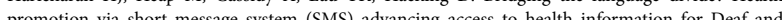
promotion va shrt Science and Society in Africa, Stellenbosch, South Africa, 18 September 2014. http://www.sayas.org. Science and Society in Africa, Stellosch, Sonth Africa, 18 se

9. Haricharan HJ, Heap M, Lau YK, Hacking D. 'So it's like a learning curve': Health promotion via short message system (SMS) advancing access to health information for signing Deaf adults in Cape Town? Presented at the Research Day, School of Public Health and Family Medicine, University of Cape Town, 25 September 2014
}

Accepted 2 November 2015 